University of Nebraska - Lincoln

DigitalCommons@University of Nebraska - Lincoln

2011

\title{
Microstructural characterization of metal foams: An examination of the applicability of the theoretical models for modeling foams
}

\author{
S.V. Raj \\ NASA Glenn Research Center, sai.v.raj@nasa.gov
}

Follow this and additional works at: https://digitalcommons.unl.edu/nasapub

Part of the Physical Sciences and Mathematics Commons

Raj, S.V., "Microstructural characterization of metal foams: An examination of the applicability of the theoretical models for modeling foams" (2011). NASA Publications. 83.

https://digitalcommons.unl.edu/nasapub/83

This Article is brought to you for free and open access by the National Aeronautics and Space Administration at DigitalCommons@University of Nebraska - Lincoln. It has been accepted for inclusion in NASA Publications by an authorized administrator of DigitalCommons@University of Nebraska - Lincoln. 


\title{
Microstructural characterization of metal foams: An examination of the applicability of the theoretical models for modeling foams
}

\author{
S.V. Raj* \\ NASA Glenn Research Center, Materials \& Structures Division, MS 106-5, 21000 Brookpark Road, Cleveland, OH 44135, USA
}

\section{A R T I C L E I N F O}

\section{Article history:}

Received 22 November 2010

Accepted 2 February 2011

Available online 18 February 2011

\section{Keywords:}

Metal foams

Cells

FeCrAlY

Kelvin cell

Matzke cell

\begin{abstract}
A B S T R A C T
Establishing the geometry of foam cells is useful in developing microstructure-based acoustic and structural models. Since experimental data on the geometry of the foam cells are limited, most modeling efforts use an idealized three-dimensional, space-filling Kelvin tetrakaidecahedron. The validity of this assumption is investigated in the present paper. Several FeCrAlY foams with relative densities varying between 3 and $15 \%$ and cells per $\mathrm{mm}$ (c.p.mm.) varying between 0.2 and 3.9 c.p.mm. were microstructurally evaluated. The number of edges per face for each foam specimen was counted by approximating the cell faces by regular polygons, where the number of cell faces measured varied between 207 and 745 . The present observations revealed that $50-57 \%$ of the cell faces were pentagonal while $24-28 \%$ were quadrilateral and $15-22 \%$ were hexagonal. The present measurements are shown to be in excellent agreement with literature data. It is demonstrated that the Kelvin model, as well as other proposed theoretical models, cannot accurately describe the FeCrAlY foam cell structure. Instead, it is suggested that the ideal foam cell geometry consists of 11 faces with 3 quadrilateral, 6 pentagonal faces and 2 hexagonal faces consistent with the 3-6-2 Matzke cell.
\end{abstract}

Published by Elsevier B.V.

\section{Introduction}

Aircraft engine noise is a major environmental concern especially in regions surrounding an airport during takeoff and landing [1]. Significant progress has been made since the advent of the first commercial jet engine-powered airplanes with current ultrahigh bypass engines being much quieter than the first generation engines. For example, the effective perceived noise level in decibels (EPNdB) relative to the International Civil Aviation Organization's (ICAO) Chapter 3 certification standards decreased from about +5 EPNdB for aircraft engines developed in the 1960s to -5 EPNdB for modern engines $[2,3]$. Despite this large improvement in engine design, there is still a great desire among policy makers and designers to reduce noise much below current levels. For example, the National Aeronautics and Space Administration (NASA) has set ambitious goals to further reduce aircraft noise by $-52 \mathrm{db}$ with respect to the newly adapted ICAO's Chapter 4 certification standards by the year 2020 under its Subsonic Fixed Wing (SFW) project [4]. It is expected that these noise reduction goals will be achieved through a combination of design changes and development of suitable materials $[3,4]$.

Polymeric foams have been historically used for sound absorption in several applications [5]. More recently, metal foams are

\footnotetext{
* Tel.: +1 216433 8195; fax: +1 2164335544 .

E-mail address: sai.v.raj@nasa.gov
}

being investigated for their flow resistance [6,7] and sound absorption properties [8-10]. Metal foams have been proposed for use in jet engines as acoustic treatment over rotors [11], fan blades [12] and other applications [13]. The acoustic and other properties of foams are dependent on their relative density, $\rho^{*} / \rho_{\mathrm{s}}$, where $\rho^{*}$ and $\rho_{\mathrm{s}}$ are the densities of the foam and the solid material, respectively, and microstructure [5]. Simple formulae exist for correlating relative density and some elements of the microstructure, such as, ligament length and thickness [5-10]. However, due to difficulties in controlling process variables, the microstructures of the foams and their properties can vary by large amounts. Although commercially manufactured foams are specified by pores per inch (p.p.i.) and their relative densities, it is noted that the reported values of p.p.i. are not necessarily identical from one manufacturer to another [14]. For example, some vendors identify the p.p.i. of their products with that of the precursor polyurethane foam rather than the finished product without accounting for metal shrinkage during the manufacturing process.

In the case of metal foams used as acoustic liners in aircraft engines, it is important to qualitatively and quantitatively understand the role their microstructures play in affecting their acoustic and mechanical properties. Since the complex threedimensional microstructures of the foams help to dissipate the sound energy, it is evident that a quantitative analysis of the foam microstructures would enable important correlations to be determined between the microstructural features and the gas pressure flow resistance as well as the sound absorption coefficients. 

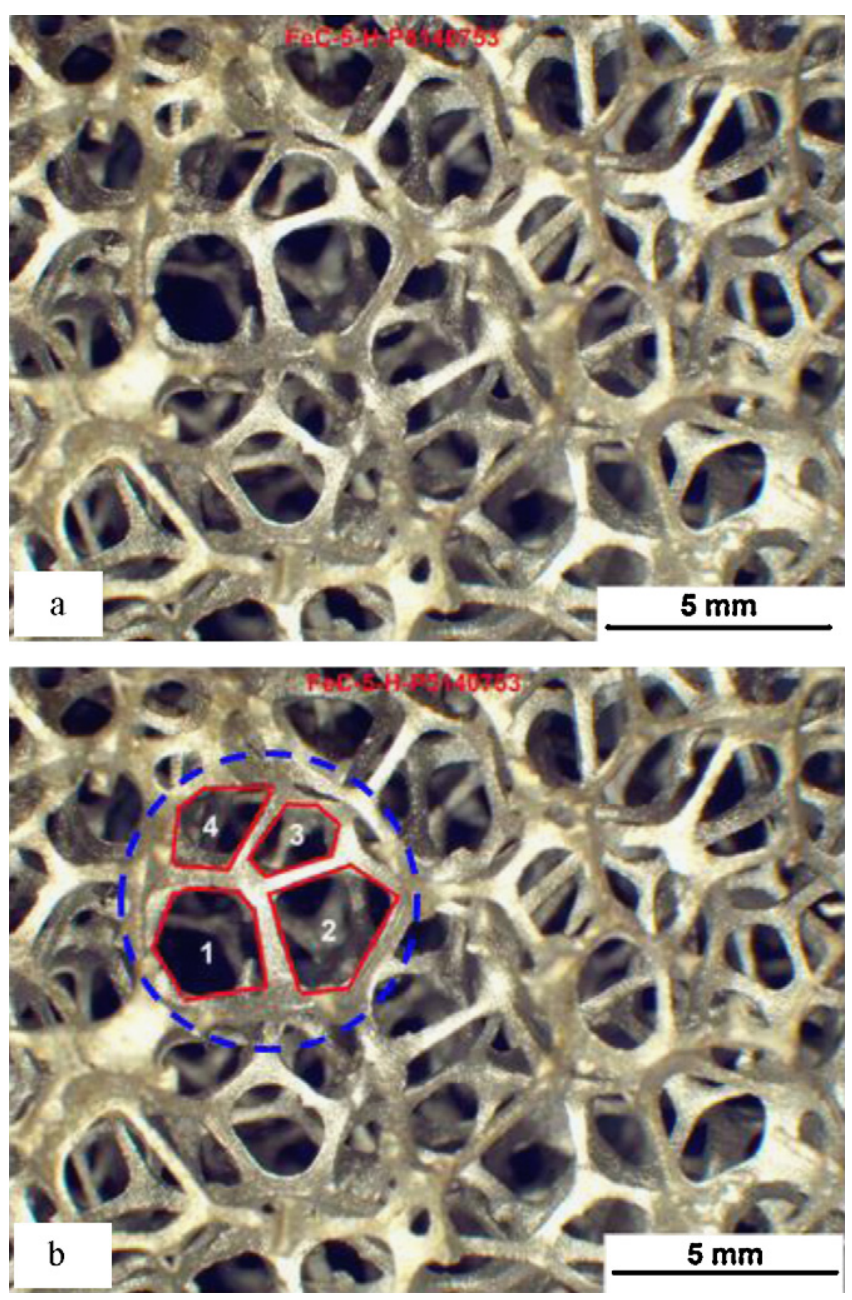

Fig. 1. (a) Optical macrograph of a FeCrAlY foam with a nominal pore density of 0.2 c.p.mm. (5 p.p.i.) and $\rho^{*} / \rho_{\mathrm{s}}=3.3 \%$; (b) polygonal representations of the faces, 1 , 2,3 and 4 enclosed by the broken circle belong to the same cell.

These correlations are essential for developing microstructurebased models for designing acoustic liners for aircraft engines. Particularly, establishing the three-dimensional topology of the cell microstructures of foams is important effectively to model fluid flow through them and to understand their mechanical properties.

Modeling activities on foam cell structures fall into two broad categories: (a) idealized topological models based on minimizing the ratio of the surface free energy to volume free energy that can fill three-dimensional (3D) space; and (b) engineering models based on the actual reconstruction of the 3D foam microstructures. Among the several possible idealized topological representations of the foam microstructures [5], the three-dimensional, space-filling Kelvin tetrakaidecahedron $[5,15,16]$ is often favored for modeling the foam cellular network. This cell has 14 faces consisting of 6 squares and 8 hexagonal faces. In other words, about $43 \%$ of the faces are squares, $0 \%$ faces are pentagonal and $57 \%$ of the faces are hexagonal. It is worth noting that other topological models have been proposed, where pentagonal faces are incorporated in the cell geometry $[17,18]$. The Kelvin model assumes that all cells are all of the same size and volume so that the problem becomes one of determining the cell shape that can pack 3D space resulting in a system with the lowest free energy [15]. In reality, cells deviate from these ideal conditions, where they may be distorted and their sizes and shapes non-uniform. Alternatively, recent computational models use actual 3D foam microstructures as an input to the model. However, these models require the availability of high-powered computational capabilities to handle the large megabytes of input data representing the foam microstructures. The input data for these models are expensive to generate, and the models tend to be rather complex. Since foam microstructures are complex, it is necessary to develop both the relatively simple and elegant topological mathematical models, as well as, the complex, but realistic, computational engineering models in order to understand the microstructure-property relationships of foams.

Several investigators have tried to evaluate the 3D shape of fat cells [19], soap bubbles [20,21], grains [22-29] and foam cells [30-33]. The measurement techniques used in these investigations include conventional microstructural image analysis, serial section metallography, optical and X-ray micro-computerized tomography $(\mu \mathrm{CT})$, magnetic resonance imaging (MRI), ultrasonic imaging and laser confocal microscopy [14,34]. Most of these procedures have advantages and disadvantages. The well-established quantitative metallography techniques [23-29,34,35] are relatively simple, inexpensive, and provide high resolution images which enable the acquisition of a large amount of statistically relevant data with relative ease. However, these procedures are destructive in nature and the 3D information of the microstructure can only be inferred from the two-dimensional (2D) sections using well-developed stereological methods $[24,25,34,35]$. The advent of powerful computers and the availability of specialized software with capabilities to reconstruct 3D images by "stitching" several closely spaced 2D images has enabled the recent development of several techniques, such as optical tomography [21], MRI [30] and $\mu \mathrm{CT}$ [32], for accurately reproducing the complex 3D foam microstructures. The primary advantages of these methods is that the resulting 3D images along with quantitative information on the foam microstructures can provide a realistic image of the 3D spatial distribution of the cells. In recent years, $\mu \mathrm{CT}$ is increasingly used to characterize foam microstructures due to the advantages of using $3 \mathrm{D}$ reconstructed images as input to the computational engineering models. Despite its relative popularity, it is time consuming, expensive and a relatively small statistical sample size than conventional metallographic methods $[31,34]$. The latter technique can reveal a statistical summary of cell shapes but it is unlikely to establish the volumetric distribution of space-filling cells unlike the 3D reconstructed images. Thus, conventional metallography can identify simple ideal cell shapes for easy mathematical modeling analysis, whereas the $3 \mathrm{D}$ reconstructed images can be directly meshed in a finite element analysis model for further analysis. However, in all instances, it is necessary to be able to distinctly identify the geometry of the cell faces.

The objectives of this investigation were to characterize the microstructures of PORVAIR ${ }^{1}$ metal foams. Quantitative information on ligament (or struts) dimensions, cell face dimensions, area fractions of open and closed faces, geometric shapes of the cell faces and distribution of ligament porosity were determined [36]. Specifically, the present paper reports statistical data on the geometrical features of the cells faces to determine the validity of the Kelvin [15] and other theoretical space-filling models [16-18] in a comprehensive manner.

\section{Experimental procedures}

Several FeCrAlY foam panels approximately $210 \mathrm{~mm} \times 210 \mathrm{~mm}$ in cross-sectional area and varying in thicknesses between 3.2 and $25.4 \mathrm{~mm}$ were procured from PORVAIR Fuel Cells Technology,

1 PORVAIR is the trademark of PORVAIR Fuel Cells Technology, Hendersonville, NC. 

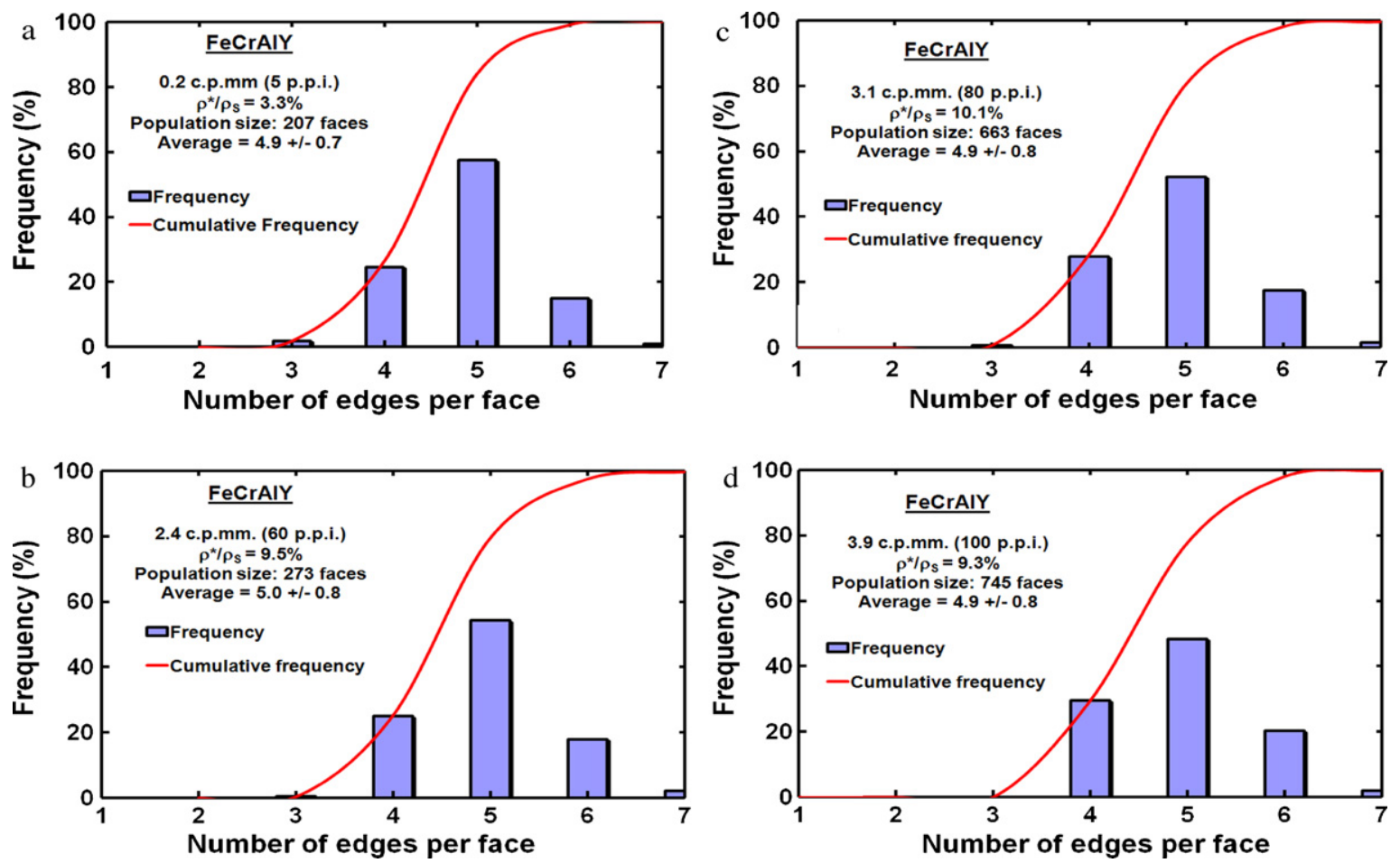

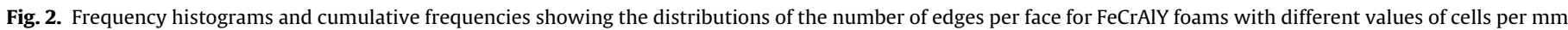
and relative densities.

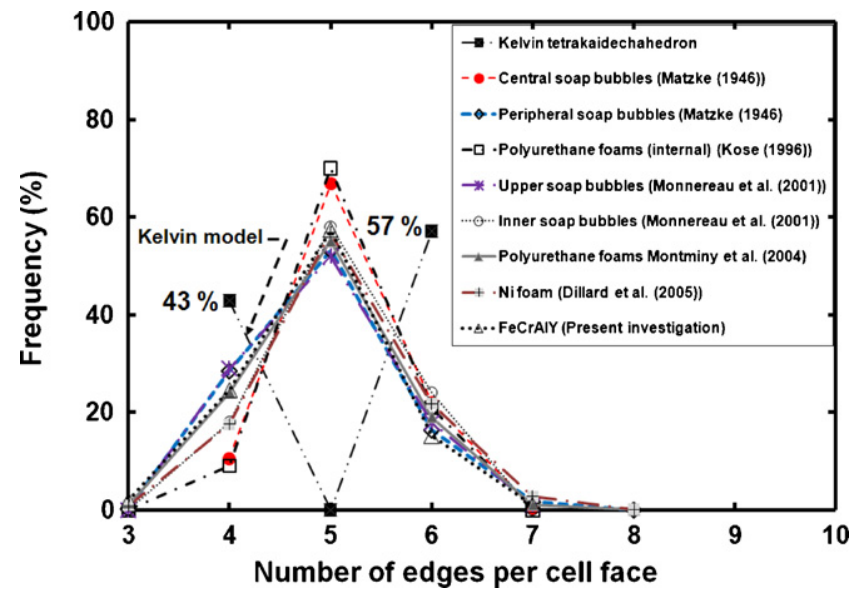

Fig. 3. Comparison of the frequency histograms of the distributions of the number of edges per face for soap bubbles [20,21], polyurethane foams [30,31], Ni foam [32] and a FeCrAlY foam with 0.2 c.p.mm. (5 p.p.i.) and $\rho^{*} \mid \rho_{\mathrm{s}}=3.3 \%$. The solid squares and associated legends represent the theoretical values for the Kelvin tetrakaidechedron.

Inc., Hendersonville, North Carolina. The c.p.mm. varied between 0.2 (5 p.p.i.) and 3.9 (100 p.p.i.), whereas $\rho^{*} / \rho_{\mathrm{S}}$ varied between 3 and $15 \%$. Square specimens $\sim 25.4 \mathrm{~mm} \times 25.4 \mathrm{~mm}$ in cross-sectional dimensions or $50 \mathrm{~mm}$ in diameter were wire electro-discharge machined from these panels for metallographic analyses.

Preliminary attempts to study the shapes of the foam cells using either $\mu \mathrm{CT}$ with resolutions varying between 20 and $100 \mu \mathrm{m}$ or an automated serial sectioning ${ }^{2}$ of a FeCrAlY foam specimen and the subsequent $3 \mathrm{D}$ reconstruction of the $2 \mathrm{D}$ sectioned images proved to be unsatisfactory since the cell ligaments were indistinct in the images. Instead, macrophotographs were obtained of the as-

\footnotetext{
2 The automated sectioning of the FeCrAlY foams and the 3D image reconstruction was conducted by UES, Inc., Dayton, $\mathrm{OH}$.
}

received foam specimens (Fig. 1(a)). This technique allowed a 3D visualization of the foam microstructure with several adjacent faces of a cell being clearly demarcated (Fig. 1(b)). It is noted that Fig. 1(a) is similar to the $3 \mathrm{D}$ reconstructed image of polymer foams [31] except that the present imaging technique is faster and cheaper. Quantitative metallographic measurements were conducted on 6-7 randomly selected areas for each foam specimen and a large number of faces were measured to ensure that the measurements were representative and to minimize measurement errors. The number of edges per face was counted by assuming that the faces could be approximated by regular polygons with the number of cell faces measured varying between 207 for foams 0.2 c.p.mm. to 745 for 3.9 c.p.mm. This assumption was not always valid since some faces were either circular or elliptical rather than polygonal and the edges were often curved. In some instances, the edges of a face curved out of the plane of view. In addition, two adjacent edges did not meet always at a relatively sharp point but had a significant curvature, while adjacent faces met at triple surfaces rather than triple points in many instances. These issues complicated the measurements and they are likely to add to the errors in measurements. Nevertheless, by measuring a large number of faces, it was felt that the errors in measurement would be minimized. It is noted that a similar method was used by Montminy et al. [31] to analyze 3D $\mu \mathrm{CT}$ images.

\section{Results and discussion}

Fig. 1(a) shows an optical macrograph of a FeCrAlY foam specimen with a nominal cell density of 0.2 c.p.mm. ( 5 p.p.i.) and $\rho^{*} / \rho_{\mathrm{S}}=3.3 \%$; Fig. 1 (b) shows the corresponding polygonal representations of the faces. The numbers identify the faces for tracking purposes. The complex nature of the foam microstructures is self evident in these figures. On close examination, it was observed that several neighboring faces were part of the same cell. For example, the faces numbered 1, 2, 3 and 4 enclosed by the broken circle represent the outer faces a single cell with some of the inner faces of the 


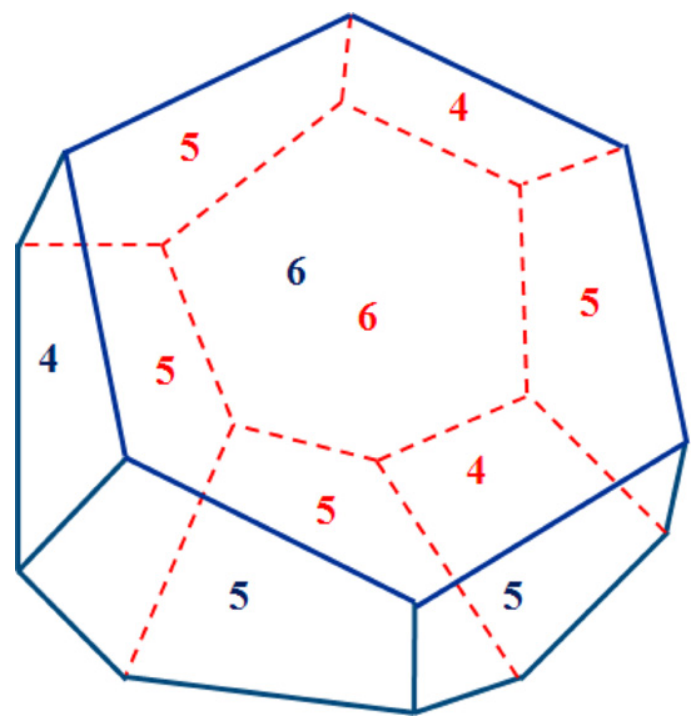

Fig. 4. A 3-6-2 eleven-hydra cell with 3 quadrilateral, 6 pentagonal and 2 hexagonal faces [20]. The numbers represent the number of edges enclosing the cell face. The blue solid lines representing the forward faces are identified by the blue lettering, while the red broken lines representing the back faces are identified by the red lettering. (For interpretation of the references to color in this figure legend, the reader is referred to the web version of the article.)

cell visible in the background (Fig. 1(b)). The volume fractions of the open cells decreased while that of the closed cells increased with increasing relative density. Since it was often difficult to clearly discern the boundaries of closed faces, only the shapes of the open faces were demarcated in these measurements in order to minimize errors in measurement. The cells were generally equiaxed irrespective of c.p.mm. and relative density.

Fig. 2(a-d) shows the frequency histogram and cumulative frequency plots of the number of edges per face for four $\mathrm{FeCrAlY}$ foams. An examination of Fig. 2(a-d) clearly establishes that $97 \%$ of the faces were either four, $n_{4}$, five, $n_{5}$, or six, $n_{6}$,-sided with over $50 \%$ of the faces being five-sided. Less than $1 \%$ of the faces were triangular and less than $2 \%$ were heptagonal except in the case of foams with 2.4 c.p.mm. (60 p.p.i.), which had about $4 \%$ heptagonal faces. The average values of the number of edges per face, $\bar{N}$, were determined to be $4.9 \pm 0.7,5.0 \pm 0.8,4.9 \pm 0.8$, and $4.9 \pm 0.8$ for the FeCrAlY foams with actual values of $\rho^{*} / \rho_{\mathrm{S}}$ being $3.3 \%$ (0.2 c.p.mm.), 9.5\% (2.4c.p.mm.), 10.1\% (3.1 c.p.mm.) and 9.3\% (3.9 c.p.mm.), respectively. The errors represent $95 \%$ confidence levels. Significantly, these observations were not influenced by either the relative densities of the foams or the lineal cell densities.

Fig. 3 compares the present results with similar measurements on soap bubbles [20,21], polyurethane foams [30,31] and Ni foam [32]. These literature data include measurements conducted on both surface and internal cells using different measurement techniques. Table 1 compares the percentages of four, five, and six-sided faces observed on the FeCrAlY foams with those reported for fat cells [19], soap bubbles [20-22], $\beta$-brass grains [22], and foams $[22,30-32]$. It is noted that the data compiled in Table 1 were obtained by several different techniques ranging from simple visual observations to complex NMR and $\mu$ CT 3D scans over a 90-year period. Significantly, in all cases, more than $50 \%$ of the cell faces had a pentagonal geometry irrespective of the material and measuring technique used (Table 1 and Fig. 3). The present results fall well within the range of other observations reported in the literature.

An examination of Fig. 3 shows that the Kelvin tetrakaidecahedron model [15], which predicts $0 \%$ five-sided faces, is inconsistent with the experimental observations. The fact that the Kelvin model fails to be consistent with the experimental results is not surprising.
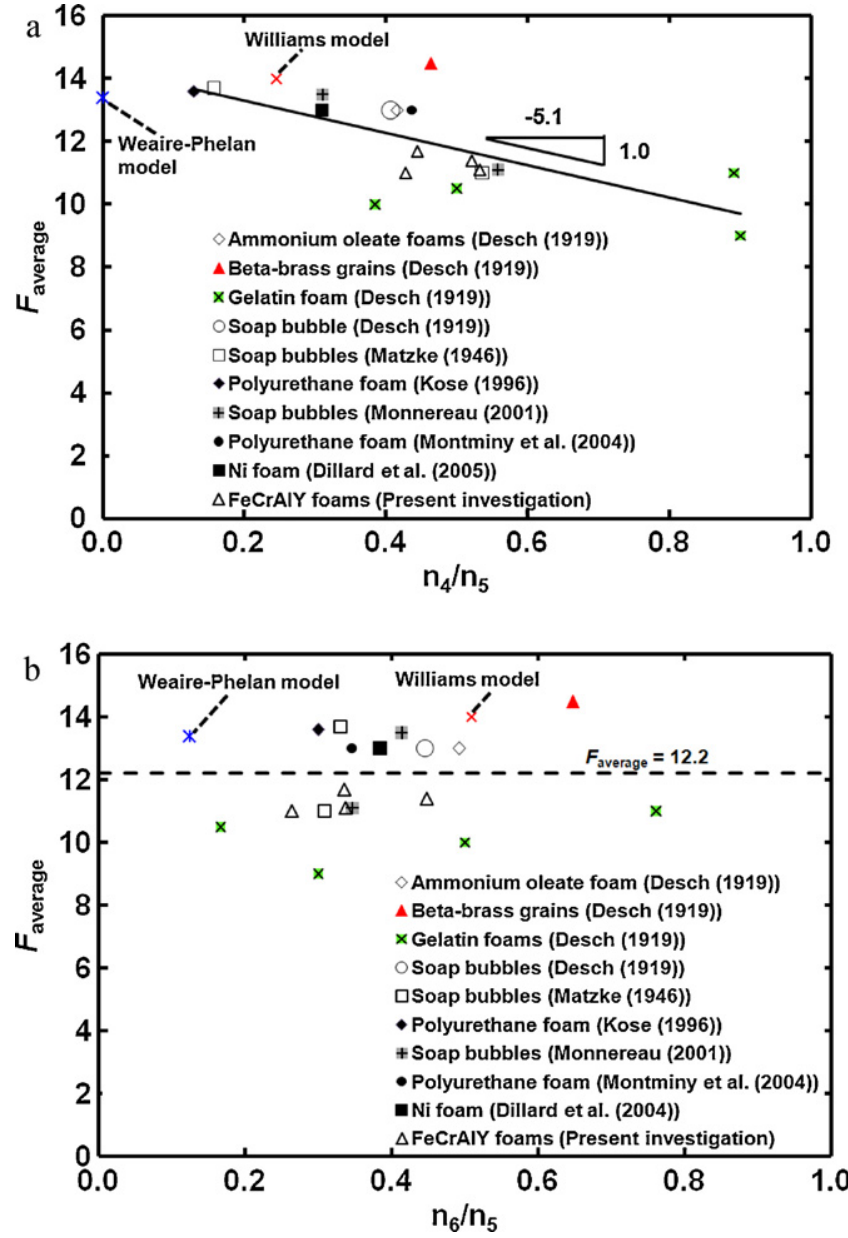

Fig. 5. Variation of the average number of cell faces against the ratio of (a) quadrilateral to pentagonal, and (b) hexagonal to pentagonal faces. The regression line through the data is represented by the solid line in (a). The present data on FeCrAlY foams are compared with literature data [20-22,30-32].

This model is based on a mathematical conjecture that soap bubbles and foam microstructures can be ideally represented by dividing three-dimensional space into cells of equal volume in a manner that follows Plateau's rules for mechanical equilibrium and minimization of the surface area [37]. It is noted that the Kelvin model requires the arrangement of tetrakaidecahedron cells to be topologically ordered and spatially periodic to fill space. Real foams are far from this ideal configuration since factors, such as residual stresses due to processing methods, topological disorder [37], unequal cell volumes, aperiodic spatial ordering of the cells [20], and thick ligaments and triple points, can influence the cell topology. Matzke [20] studied 400 peripheral soap bubbles and observed that the largest number of them possessed eleven-hedra cells with 3 four-sided, 6 five-sided and 2 six-sided faces (3-6-2) $)^{3}$ (Fig. 4). However, these soap bubbles only constituted $17 \%$ of the total number of bubble studied since twenty other shapes were observed. In contrast, 97\% of the cell faces in the FeCrAlY foams were either four, five or sixsided. Therefore, it would be interesting to determine the number of faces for the ideal cell representing the microstructures of the FeCrAlY foams.

Since quantitative optical metallography gives 2D information, the 3D topographical characteristics of the microstructure can be determined from well established streology equations

3 This nomenclature of identifying the cells was suggested by Kraynik et al. [37]. 
Table 1

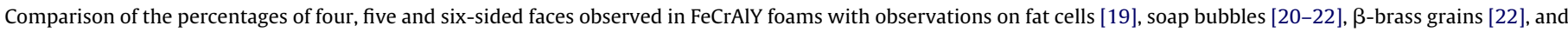
foams [22,30-32].

\begin{tabular}{|c|c|c|}
\hline Description & Measurement technique & Percentage of polyhedral faces, $n_{4}, n_{5}$ and $n_{6}$ \\
\hline Fat cells (Lewis [19]) & Optical microscopy or visual & $n_{4}=21 \% ; n_{5}=53 \% ; n_{6}=23 \%$ \\
\hline Soap bubbles (Matzke [20]) & Optical microscopy & $\begin{array}{l}\text { Peripheral: } n_{4}=29 \% ; n_{5}=53 \% ; n_{6}=16 \% \\
\text { central: } n_{4}=11 \% ; n_{5}=67 \% ; n_{6}=22 \%\end{array}$ \\
\hline $\begin{array}{l}\text { Soap bubbles (Monnereau et al. } \\
\text { [21]) }\end{array}$ & Optical tomography & $\begin{array}{l}\text { Upper bubbles: } n_{4}=29 \% ; n_{5}=52 \% ; n_{6}=18 \% \text {; } \\
\text { internal bubbles: } n_{4}=18 \% ; n_{5}=58 \% ; n_{6}=24 \%\end{array}$ \\
\hline$\beta$-Brass grains & \multirow[t]{4}{*}{ Visual } & $n_{4}=20 \% ; n_{5}=44 \% ; n_{6}=28 \%$ \\
\hline Soap bubbles & & $n_{4}=20 \% ; n_{5}=50 \% ; n_{6}=22 \%$ \\
\hline Ammonium oleate foams & & $n_{4}=21 \% ; n_{5}=50 \% ; n_{6}=25 \%$ \\
\hline $\begin{array}{l}\text { Gelatin foams } \\
\text { (Desch [22]) }\end{array}$ & & $n_{4}=19-38 \% ; n_{5}=32-57 \% ; n_{6}=10-25 \%$ \\
\hline Polyurethane foams (Kose & \multirow[t]{2}{*}{ NMR $\mu \mathrm{CT}$} & $n_{4}=9 \% ; n_{5}=70 \% ; n_{6}=21 \%$ \\
\hline [30]) (Montminy et al. [31]) & & $n_{4}=24 \% ; n_{5}=55 \% ; n_{6}=19 \%$ \\
\hline $\begin{array}{l}\text { Open cell Ni foam (Dillard et al. } \\
{[32] \text { ) }}\end{array}$ & $\mu \mathrm{CT}$ & $n_{4}=18 \% ; n_{5}=57 \% ; n_{6}=22 \%$ \\
\hline \multirow[t]{6}{*}{$\begin{array}{l}\text { FeCrAlY foams (present } \\
\text { investigation) }\end{array}$} & \multirow[t]{6}{*}{ Optical microscopy } & $\begin{array}{l}n_{4}=25 \% ; n_{5}=57 \% ; n_{6}=15 \% \text { ( } 0.2 \text { c.p.mm.; } \\
\left.\rho^{*} / \rho_{\mathrm{s}}=3.3 \%\right)\end{array}$ \\
\hline & & $n_{4}=24 \% ; n_{5}=54 \% ; n_{6}=18 \%$ (2.4 c.p.mm.; \\
\hline & & $\left.\rho^{*} / \rho_{\mathrm{s}}=9.5 \%\right)$ \\
\hline & & $n_{4}=28 \% ; n_{5}=52 \% ; n_{6}=18 \%$ (3.1 c.p.mm.; \\
\hline & & $\left.\rho^{*} / \rho_{\mathrm{s}}=10.1 \%\right)$ \\
\hline & & $\begin{array}{l}n_{4}=26 \% ; n_{5}=50 \% ; n_{6}=22 \% \text { (3.9 c.p.mm.; } \\
\left.\rho^{*} / \rho_{s}=9.3 \%\right)\end{array}$ \\
\hline
\end{tabular}

[23-29,34,35,38-40]. The number of faces per cell, $F$, the number of edges per cell, $E$, and the number of vertices per cell, $V$, of the 3D cell are related by the Euler equation $[5,25,34,39]$ and they can be determined from $\bar{N}$ using the Coxeter equations [41]

$F=\frac{12}{[6-\bar{N}]}$

$E=\frac{6 \bar{N}}{[6-\bar{N}]}$

$V=\frac{4 \bar{N}}{[6-\bar{N}]}$

Table 2 shows the calculated values of $F, E, V$, and the corresponding experimental values of $N_{4}, N_{5}$ and $N_{6}$ for the four FeCrAlY foams. ${ }^{4}$ Using the measured values of $\bar{N}$, the corresponding values of $F$ calculated from Eq. (1a) are 11.0, 11.7, 11.1 and 11.4 for foams with 0.2 (5 p.p.i.), 2.4 (60 p.p.i.), 3.1 (80 p.p.i.) and 3.9 c.p.mm. (100 p.p.i.), respectively. Based on these results, the topological characteristics of the ideal PORVAIR foam cell are: $F=11, E=27$ and $V=18$, which satisfy Euler's theorem (i.e. $V-E+F=2$ ) with $N_{4}=3, N_{5}=6$ and $N_{6}=2$. These values are independent of relative density.

Table 3 compares the topological features of the FeCrAlY foams with several simple cell shapes [5], where $C$ is the number of cells. The topological characteristics of the FeCrAlY foams do not agree with any of these simple geometries. Instead, they appear to be closer to the topological structure of clathrates although more detailed topological modeling needs to be conducted to establish this possibility $[42,43]$. As noted above, Matzke [20] observed that most of the peripheral soap bubbles were eleven-hedra cells with 3 four-sided, 6 five-sided and 2 six-sided faces (3-6-2). Based on the excellent agreement between the present results and Matzke's data on peripheral soap bubbles [20] (Fig. 3) taken together with the fact that the total number of faces for the FeCrAlY foams was determined to be 11 (Table 2), it is reasonable to suggest that the eleven-hedra 3-6-2 cell is the most representative of the FeCrAlY foam cellular structure.

Table 4 shows the predicted [15-18] and the experimental $[20,21,30]$ percentage distributions of polyhedral faces and the

\footnotetext{
${ }^{4}$ In this paper, $n_{i}$ represents the percentage of faces with $i$ edges, whereas $N_{i}$ is number of such faces enclosing the cell.
}

average number of faces per cell, $F_{\text {average }}$. As noted earlier, the data were obtained by different methods on several materials over a 90 -year period. The average value of $F=11.3$ determined for the FeCrAlY foam cells (Table 2 ) is in very good agreement with the experimental observations on the peripheral [20] or upper [21] soap bubbles and gelatin foams [22] for which the average number of faces is about 11 .

A close examination of Table 4 reveals that the present results do not agree with the predictions of the three topological models [15-18]. The Kelvin cell [15] does not possess any pentagonal faces, whereas the Weaire-Phelan model $[16,18,30]$ does not have any quadrilateral faces, with the total number of faces being either 14 or 13.4, respectively. The Williams cell [17] with 14 faces possesses $14 \%$ quadrilateral, $57 \%$ pentagonal and $29 \%$ hexagonal faces. However, this model also does not agree with the present observations on the FeCrAlY foams. This difference between the experimental results and the theoretical predictions is to be expected since theoretical efforts mainly consider the surface and volume free energy contributions to the total free energy [37]. As indicated earlier, other factors can influence the final cell topology of real foams. For example, the effects of residual stresses developed in the foam panels during processing are not included in these theoretical derivations. Qualitatively, one can modify the Gibbs free energy equation as follows:

$\Delta G=\left(\Delta g_{\mathrm{v}}+\Delta g_{\mathrm{e}}\right) \times V_{\mathrm{C}}+\Delta g_{\mathrm{s}} \times S_{\mathrm{C}}$

where, $\Delta G, \Delta g_{\mathrm{v}}, \Delta g_{\mathrm{e}}$ and $\Delta g_{\mathrm{s}}$ are the changes in the total, volume, residual strain and surface Gibbs free energies, respectively, $V_{C}$ is the cell volume and $S_{\mathrm{C}}$ is the surface are of the cell. It is important to note that current theoretical models agree incorrectly assume that $\Delta g_{\mathrm{e}}=0$ for real foams.

Table 4 shows that $F_{\text {average }}$ varied between 9.0 and 14.5 [20-22,30]. On further examination of the data, $F_{\text {average }}$ decreases linearly with the increasing ratio, $n_{4} / n_{5}$ (Fig. 5(a))

$F_{\text {average }}=-5.1\left(\frac{n_{4}}{n_{5}}\right)+14.3 \quad\left(R_{\mathrm{d}}^{2}=0.461\right)$

where $R_{\mathrm{d}}^{2}$ is the coefficient of determination. In contrast, it is independent of $n_{6} / n_{5}$ (Fig. 5(b)). The regression Eq. (3) is represented by the solid line in Fig. 5(a); the broken horizontal line in Fig. 5(b) represents the average value of $F_{\text {average }}=12.2$ for all the data. Eq. (3) predicts a value of $F_{\text {average }}=14.3$ for $n_{4}=0, F_{\text {average }}=9.2$ for $n_{4}=n_{5}$. 
Table 2

Calculated values of $F, E, V, N_{4}, N_{5}$ and $N_{6}$ for FeCrAlY foams.

\begin{tabular}{|c|c|c|c|c|c|c|c|}
\hline Linear cell density (c.p.mm.) & $\rho^{*} \mid \rho_{\mathrm{s}}(\%)$ & $F$ & E & V & $N_{4}$ & $N_{5}$ & $N_{6}$ \\
\hline 0.2 (5 p.p.i.) & 3.3 & 11.0 & 26.7 & 17.8 & 3 & 6 & 2 \\
\hline 2.4 (60 p.p.i.) & 9.5 & 11.7 & 30.0 & 20.0 & 3 & 6 or 7 & 2 \\
\hline 3.1 (80 p.p.i.) & 10.1 & 11.1 & 26.7 & 17.8 & 3 & 6 & 2 \\
\hline 3.9 (100 p.p.i.) & 9.3 & 11.4 & 26.7 & 17.8 & 3 & 6 & 2 or 3 \\
\hline Average & & 11.3 & 27.5 & 18.4 & 3 & 6 & 2 \\
\hline
\end{tabular}

Table 3

Comparison of the geometric properties of FeCrAlY foam cells with those for simple polyhedra [5].

\begin{tabular}{|c|c|c|c|c|c|c|c|c|c|}
\hline \multirow[t]{2}{*}{ Cell shape } & \multicolumn{3}{|c|}{ Number of face shapes } & \multirow[b]{2}{*}{6} & \multirow[t]{2}{*}{$F$} & \multirow[t]{2}{*}{ E } & \multirow[t]{2}{*}{$V$} & \multirow[t]{2}{*}{ C } & \multirow[t]{2}{*}{ Remarks } \\
\hline & 3 & 4 & 5 & & & & & & \\
\hline Tetrahedron & 4 & - & - & - & 4 & 6 & 4 & 1 & Regular platonic solid \\
\hline Triangular prism & 2 & 3 & - & - & 5 & 9 & 6 & 1 & Packs to fill space \\
\hline Square prism & - & 6 & - & - & 6 & 12 & 8 & 1 & Packs to fill space \\
\hline Hexagonal prism & - & 6 & - & 2 & 8 & 18 & 12 & 1 & Packs to fill space \\
\hline Octahedron & 8 & - & - & - & 8 & 12 & 6 & 1 & Regular platonic solid \\
\hline Rhombic dodecahedron & - & 12 & - & - & 12 & 24 & 14 & 1 & Packs to fill space \\
\hline Pentagonal dodecahedron & - & - & 12 & - & 12 & 30 & 20 & 1 & Regular platonic solid \\
\hline Tetrakaidecahedron & - & 6 & - & 8 & 14 & 36 & 24 & 1 & Packs to fill space \\
\hline Icosahedron & 20 & - & - & - & 20 & 30 & 12 & 1 & Regular platonic solid \\
\hline $3-6-2$ cell & - & 3 & 6 & 2 & 11 & 27 & 18 & 1 & FeCrAlY foam (present investigation) \\
\hline
\end{tabular}

Table 4

Comparison of the geometric properties of the cells predicted by several theoretical models [15-18] and experimental data [20-22,30-32].

\begin{tabular}{|c|c|c|}
\hline Description & Percentage of polyhedral faces, $n_{4}, n_{5}$ and $n_{6}$ & $F_{\text {average }}$ \\
\hline Kelvin cell [15] & $n_{4}=43 \% ; n_{5}=0 \% ; n_{6}=57 \%$ & 14 \\
\hline Williams cell [17] & $n_{4}=14 \% ; n_{5}=57 \% ; n_{6}=29 \%$ & 14 \\
\hline Weaire and Phelan model $[16,18]$ & $n_{4}=0 \% ; n_{5}=89 \% ; n_{6}=11 \%$ & 13.4 \\
\hline \multirow[t]{2}{*}{ Soap bubbles (Matzke [20]) } & Peripheral: $n_{4}=29 \% ; n_{5}=53 \% ; n_{6}=16 \%$ & 11.0 (peripheral) \\
\hline & Central: $n_{4}=11 \% ; n_{5}=67 \% ; n_{6}=22 \%$ & 13.7 (central) \\
\hline \multirow[t]{2}{*}{ Soap bubbles (Monnereau et al. [21]) } & Upper bubbles: $n_{4}=29 \% ; n_{5}=52 \% ; n_{6}=18 \%$ & 11.1 (upper bubbles) \\
\hline & Internal bubbles: $n_{4}=18 \% ; n_{5}=58 \% ; n_{6}=24 \%$ & 13.5 (internal bubbles) \\
\hline$\beta$-Brass grains & $n_{4}=20 \% ; n_{5}=44 \% ; n_{6}=28 \%$ & 14.5 \\
\hline Soap bubbles & $n_{4}=20 \% ; n_{5}=50 \% ; n_{6}=22 \%$ & 13.0 \\
\hline Ammonium oleate foams & $n_{4}=21 \% ; n_{5}=50 \% ; n_{6}=25 \%$ & 13.0 \\
\hline Gelatin foams (Desch [22]) & $n_{4}=19-38 \% ; n_{5}=32-57 \% ; n_{6}=10-25 \%$ & $9.0-11.0$ \\
\hline \multirow{2}{*}{$\begin{array}{l}\text { Polyurethane foam (Kose [30]) } \\
\text { (Montminy et al. [31]) }\end{array}$} & $n_{4}=9 \% ; n_{5}=70 \% ; n_{6}=21 \%$ & 13.6 \\
\hline & $n_{4}=24 \% ; n_{5}=55 \% ; n_{6}=19 \%$ & 13.0 \\
\hline $\begin{array}{l}\text { Open cell Ni foam } \\
\text { (Dillard et al. [32]) }\end{array}$ & $n_{4}=17.6 \% ; n_{5}=56.8 \% ; n_{6}=21.8 \%$ & 13.0 \\
\hline FeCrAlY foams (present investigation) & $n_{4}=24-28 \% ; n_{5}=50-57 \% ; n_{6}=15-22 \%$ & 11.3 \\
\hline
\end{tabular}

Two important points can be discerned from Fig. 5(a) and (b) and Eq. (3). First, the experimental data in Fig. 5(a) are scattered around the regression line described by Eq. (3) irrespective of the either the materials studied or the method used for determining the shape of the cells. Second, the magnitude of $F_{\text {average }}$ depends only on the ratio $n_{4} / n_{5}$ and it is not influenced by variations in $n_{6} / n_{5}$.

\section{Summary and conclusions}

A detailed microstructural analysis of several FeCrAlY metal foams with relative densities varying between 3 and $15 \%$, and linear cell densities varying between 0.2 and 3.9 c.p.mm., was conducted to evaluate the topology of the foam cells. The shapes of cell faces were evaluated by approximating the faces by regular polygons. It was observed that between 24 and $28 \%$ of the cell faces were quadrilateral, 50-57\% pentagonal, and 15 to $22 \%$ hexagonal in morphology. The present results are in excellent agreement with observations on soap bubbles [20,21]. Based on Matzke's observations [20], it is suggested that the FeCrAlY foam cells had a total of 11 faces with 3 quadrilateral, 6 pentagonal and 2 hexagonal faces. Both sets of results do not agree with the 14-hedra Kelvin tetrakaidecahedron model [15], which only has 43 and 57\% quadrilateral and hexagonal faces, respectively. Neither do the present results agree with the
Williams [17] and Weaire-Phelan models [16,18,30] models. The present calculations show that the 3-6-2 cell, which probably best describes the FeCrAlY foam cells, has 27 edges and 18 vertices. A compilation of 90 years of experimental data reveals that the average number of cell faces decreases linearly with the increasing ratio of quadrilateral to pentagonal faces. It is concluded that the Kelvin model is not supported by these experimental data.

\section{Acknowledgements}

The investigation was funded by NASA's Subsonic Fixed Wing Program. Discussions with Prof. John Russ, North Carolina State University, N.C., and Dr. Don Roth, NASA Glenn Research Center, Cleveland, $\mathrm{OH}$, are gratefully acknowledged.

\section{References}

[1] J.L. Kerrebrock, Aircraft Engines and Gas Turbines, The MIT Press, Cambridge, MA, 1992.

[2] B.L. Koff, J. Propulsion Power 20 (2004) 577-595.

[3] D.L. Huff, E. Envia, in: M.J. Crocker (Ed.), Handbook of Noise and Vibration Control, John Wiley, Hoboken, NJ, 2007, pp. 1090-1102.

[4] E. Envia, R. Thomas, Research Progress in Aircraft Noise Research, ARMD Technical Seminar October 16, 2007, http://ntrs.nasa.gov/archive/ nasa/casi.ntrs.nasa.gov/20080006600_2008004016.pdf, NASA Glenn Research Center, Cleveland, OH, 2007. 
[5] L.J. Gibson, M.F. Ashby, Cellular Solids, Cambridge University Press, Cambridge, UK, 1997.

[6] C.Y.Zhao, T. Kim, T.J. Lu, H.P. Hodson, Thermal Transport Phenomena in Porvair Metal Foams and Sintered Beds, Final Report, August 2001, Micromechanics Centre \& Whittle Lab., Department of Engineering, University of Cambridge, Cambridge, UK, 2001.

[7] T.J. Lu, M. Kepets, A.P. Dowling, Sci. China Ser E-Technol. Sci. 51 (2008) 1803-1811.

[8] T.J. Lu, A. Hess, M.F. Ashby, J. Appl. Phys. 85 (1999) 7528-7539.

[9] T.J. Lu, F. Chen, D. He, J. Acoustic Soc. Am. 108 (2000) 1697-1709.

[10] T.J. Lu, M. Kepets, A.P. Dowling, Sci. China Ser. E-Technol. Sci. 51 (2008) 1812-1837.

[11] D.L. Sutliff, D.M. Elliott, M.G. Jones, T.C. Hartley, Attenuation of FJ44 Turbofan Engine Noise With a Foam-Metal Liner Installed Over-the-Rotor, NASA TM2009-215666, NASA Glenn Research Center, Cleveland, OH, 2009.

[12] S.V. Raj, L.J. Ghosn, B.A. Lerch, M. Hebsur, L.M. Cosgirff, M. Topolski, An Evaluation of Lightweight 17-4PH Stainless Steel Foam Design Concepts for Fan and Propeller Blade Applications, NASA TM-2005-213620, NASA Glenn Research Center, Cleveland, OH, 2005.

[13] W.E. Azzi, W.L. Roberts, A. Rabiei, Mater. Res. Soc. Symp. Proc. 851 (2005), p. NN11.3.

[14] S. Mullens, J. Luyten, J. Zeschky, in: M. Scheffler, P. Colombo (Eds.), Characterization of Structure and Morphology, Cellular Ceramics: Structure, Manufacturing, Properties and Applications, Wiley-VCH Verlag GmbH \& Co. KGaA, 2005, pp. 227-266.

[15] W. Thompson, Philos. Mag. 24 (1887) 503-514.

[16] D. Weaire, S. Hutzler, The Physics of Foams, Oxford University Press, Oxford, UK, 1999.

[17] R.E. Williams, Science 161 (1968) 276-277.

[18] D. Weaire, R. Phelan, Philos. Mag. Lett. 70 (1994) 345-350.

[19] F.T. Lewis, Am. Acad. Arts Sci. 61 (1925) 1-34.

[20] E.B. Matzke, Am. J. Bot. 33 (1946) 58-80.

[21] C. Monnereau, B. Prunet-Foch, M. Vignes-Adler, Phys. Rev. E 63 (2001) 061402.
[22] C.H. Desch, J. Inst. Metals 22 (1919) 241-266.

[23] D. Harker, E.R. Parker, Trans. ASM 34 (1945) 156-201.

[24] C.S. Smith, Trans. AIME 175 (1948) 15-51.

[25] C.S. Smith, Metal Interfaces, American Society for Metals, Cleveland, OH, 1952 pp. 63-113.

[26] C.S. Smith, Rev. Modern Phys. 36 (1964) 524-532.

[27] D.A. Aboav, T.G. Langdon, Metallography 2 (1969) 171-178.

[28] K. Ejiri, J. Cryst. Growth 19 (1973) 77-78.

[29] M.D. Higgins, Am. Miner. 85 (2000) 1105-1116.

[30] K. Kose, J. Magn. Resonance A118 (1996) 195-201.

[31] M.D. Montminy, A.R. Tannenbaum, C.W. Macosko, J. Colloid Interf. Sci. 280 (2004) 202-211.

[32] T. Dillard, F. N'Guyen, E. Maire, L. Salvo, S. Forest, Y. Bienvenu, J.D. Bartout, M. Croset, R. Denievel, P. Cloetens, Philos. Mag. 85 (2005) 2147-2175.

[33] A.P. Roberts, in: M. Scheffler, P. Colombo (Eds.), Cellular Ceramics: Structure, Manufacturing, Properties and Applications, Wiley-VCH Verlag GmbH \& Co. KGaA, 2005, pp. 267-288.

[34] J.C. Russ, R. DeHoff, Practical Stereology, Kluwer Academic/Plenum Publishers, New York, NY, 2000.

[35] R.T. DeHoff, G.Q. Liu, Metall. Trans. 16A (2007) 1985-2011.

[36] S. V. Raj, J. A. Kerr, Metall., (2011) doi:10.1007/s11661-010-0573-z.; S. V. Raj, J. A. Kerr, NASA/TM-2010-216342/REV1, Glenn Research Center, Cleveland, OH (2010).

[37] A.M. Kraynik, D.A. Reinelt, F.V. Swol, Phys. Rev. Lett. 93 (2004) 208301.

[38] C.S. Smith, L. Guttman, Trans. AIME 197 (1953) 81-87.

[39] C.S. Smith, Trans. ASM 45 (1953) 533-575.

[40] T.D. Peterson, Contrib. Mineral. Petrol. 124 (1996) 395-405.

[41] H.S.M. Coxeter, Illinois J. Mathvol. 2 (1958) 746-758.

[42] V.I. Kosyakov, J. Struct. Chem. 37 (1996) 106-113.

[43] H. Tomono, H. Eguchi, K. Tsumuraya, J. Phys.: Condens. Matter 20 (2008) 385209, doi:10.1088/0953-8984/20/38/385209. 